number alter glucocorticoid injection into fetal rabbits to enhance surfactant appearance. Pediatrics, 53: 358 (1974).

36. Lavin, N., Rachelefsky. (;., and Kaplan. S. A.: Inhibition of cyclic-AMP phosphodiesterase in human lymphocytes by physiological concentrations of hydrocortisone. Horm. Metab. Res. 7: 253 (1975).

37. Levey, G. S., and Epstein. S. E.: Myocardial adenyl cyclase: Activation by thyroid hormones and evidence for two adenyl cyclase systems. J. Clin. Invest. 48: $1663(1969)$

38. Liggins, G. C .: Premature delivery of foetal lambs infused with glucocorticoids. J. Endocrinol.. 45: $515(1969)$

39. L.iggins, G. C.. and Howic, R. N.: A cont rolled trial of antepartum glucocorticoid treatment for prevention of the respiratory distress syndrome in premature infants. Pediatrics, 50: 515 (1972).

40. L.owry, O. H., Rosebrough, N. J.. Farr, A. L., and Randall, R. J.: Protein measurement with the Folin phenol reagent. J. Biol. Chem.. 193: 265 (1951).

41. Manganiello, V., and Vaughan, M.: An effect of dexamethasone on adenosine $3^{\prime}, 5^{\prime}$-monophosphate content and adenosine $3^{\prime}, 5^{\prime}$-monophosphate phosphodiesterase activity of cultured hepatoma cells J Clin. Invest. 51: 2763 (1972)

42. Menon. K. M. J.. Giese, S., and Jaffe, R. B.: Hormone- and fluoride-sensitive adenylate cyclases in human fetal tissues. Biochim. Biophys. Acta, 304: 203 (197.3).

43. Moskowitz, J., and Fain, J. N.: Stimulation by growth hormone and dexamethatsone of labeled cyclic adenosine $3^{\prime} 5^{\prime}$-monophosphate accumulation by white fat cells. J. Biol. Chem., 245: 1101 (1970).

44. Motoyama. E. K.. Orzalesi. M. M.. Kikkawa. Y., Kaibara, M., Wu, B., Ligas, C J., and Cook. C. D.: Effect of cortisol on the maturation of fetal rabbit lungs. Pediatrics, 48: 547 (197i)

45. Palmer, G. C.: Characteristics of the hormonal induced evelic adenosin $3^{\prime} .5^{\prime}$-monophosphate response of the rat and guinea pig lung in vitro. Biochim. Biophys. Acta, 252: 561 (1971).

46. Palmer. G. C.: Cyelic 3',5'-adenosine monophosphate response in the rabbit lung-adult properties and development. Biochem. Pharmacol., 21: 2907 (1972).

47. Redding. R. A.. Douglas, W. H. J., and Stein. M.: Thyroid hormone influence upon lung surfactant metabolism. Science. 175: 994 (1972).

48. Reynolds, E. O. R.. Orzalesi, M. M., Motoyama, E. K., Craig, J. M.. and Cook.
C. D.: Surface propertes of saline ext racts from lungs of newborn infants. Acta Pilediat. Scand. 54:511 (1965).

49. Rooney, S. A.. Gross, I. Motoyama, E. K., and Warshaw. J. B.: Effects of cortisol and thyroxine on fatty acid and phospholipid biosynthesis in fetal rabbit lung. Physiologist, 17: 323 (1974).

50. Russell, B. J. Nugent, L., and Chernick, V. Effects of steroids on the enzymatic pathways of lecithin production in fetal rabbits. Biol. Neonate, 24 306 (1974)

51. Russell, T. R.. Terasaki, W. I... and Appleman. M. M.: Separate phosphodiesterases for the hydrolysis of cyclic adenosine $3{ }^{\prime} .5^{\prime}$-monophosphate and cyclic guanosine 3'.5'-monophosphate in rat liver. J. Biol. Chem., 248: 1334 (1973).

52. Schack. J. A. and Waxker. S. H.: An ultraviolet spectrophotometric method for the determination of theophylline and theobromine in blood and tissues. J. Pharmacol. Exp. Ther., 97: 283 (1949).

53. Senft, G., Schultz. G.. Munske, K.. and Hoffman. M.: Effects of glucocorticoids and insulin on $3^{\prime}, 5^{\prime}$-AMP phosphodiesterase activity in adrenalectomized rats. Diabetologia. 4: 330 (1968).

54. Shipiro, S. Some physiologic biochemicil and behavioral consequences of neonatal hormone administration: Cortisol and thyroxin. Gen. Comp. Endocrinol., 10: $214(1968)$

55. Snedecor, G. W.. and Cochran, W. G.: Statistical Methods, Ed. 6 (Iowa Stute University Press. Ames, Jowa. 1967).

56. Stahlman, M. T., Gray, M. E., Lieu, S., and Chytil, F.: The role of cyclic AMP in lamellar body synthesis and secretion. Pediat. Res, 8: 470 (1974).

57. Wellman, K. F., and Volk, B. W.: Fine structural changes in the rabbit placenta induced by cortisone. Arch. Pathol., 94: 147 (1972).

58. Wu. B.. Kikkawa, Y.. Orzalesi. M. M.. Motoyama. E. K., Kaibara, M.. Zigas, C. J., and cook, C. D.: The effect of thyroxine on the maturation of fetal rabbit lungs. Biol. Neonate. 22: 161 (1973).

59. This research was supported in part by United States Public Health Service Grant No. HD 05.443. University General Research Support funds, and the California Research and Medical Education Fund of the California Lung Association

60. Requests for reprints should be addressed to: C. T. Barrett. M.D. Department of Pediatrics. UCLA School of Medicine. Los Angeles, Calif. 90024 (USA)

61. Accepted for publication January 14, 1976.

\title{
Enzymatic Diagnosis and Carrier Detection of Aspartylglucosaminuria Using Blood Samples
}

\author{
PERTTI AULA, ${ }^{23}$ KARI RAIVIO, AND SFPPO AUTIO
}

Children's Hospital and Third Department of Pathology, University of Helsinki, Helsinki, Finland

Extract

The activity of the glycoprotein degrading lysosomal hydrolase, 4-L-aspartylglycosylamine amido hydrolase (AADGase, EC.3.5.1.26), was measured in plasma, buffy coat leukocytes, and separated lymphocytes (Ficoll separation) from 16 patients with aspartylglucosaminuria (AGU), 29 obligate heterozygotes, and 30 control subjects. In lymphocytes the AGU patients had unmeasurable or minimal AADGase activity with a mean of 3.9 U. The obligate heterozygotes showed AADG ase activities ranging from 5 to 69 $\mathrm{U}$ with a mean of $34.1 \mathrm{U}$. Enzyme activities in the control group ranged from 91 to $243 \mathrm{U}$ with a mean of $127.9 \mathrm{U}$, and were clearly separated from the values of the heterozygotes.

In leukocytes the AGU patients had unmeasurable enzyme activity and obligate heterozygotes had enzyme levels closely similar to those in the lymphocytes from the same individuals. The
AADGase activity in the leukocytes of the control group displayed a much wider variation than in the lymphocytes, ranging from 22 to $132 \mathrm{U}$ with a mean of $70.7 \mathrm{U}$.

In plasma the AGU patients had undetectable AADGase activity. The mean enzyme level of obligate heterozygotes was $72.2 \mathrm{U}$ and that of control individuals $107.2 \mathrm{U}$, but the overlap between the groups was extensive. The results indicate that homozygous deficiency of A AD Gase, i.e., aspartylglucosaminuria, can be reliably diagnosed using plasma, leukocytes, or separated lymphocytes. For carrier detection only separated lymphocytes allow a satisfactory differentiation between heterozygous and normal individuals.

A group of 31 siblings of verified A GU cases and 11 children of identified carriers, whose spouses had normal AADGase activity, were investigated using the lymphocyte assay. The observed and expected frequencies (on the basis of Mendelian probabilities) were closely similar, suggesting that the lymphocyte assay can be used reliably for carrier detection. 


\section{Speculation}

Demonstration of AADGase deficiency in plasma or in white blood cells offers an alternative method for the diagnosis of aspartylglucosaminuria. Large scale screening programs for AGL carrier detection with the lymphocyte enzyme assay are not considered practical and justified at present. Carrier screening among relatives of known AGU patients is, however, medically, econemically, and psychologically advantageous, particularly since prenatal diagnosis and the possibility of preventive abortion can be offered to carrier-carrier matings.

Deficiency of the lysosomal enzyme, 4-L-aspartylglycosylamine a mido hydrolase, causes a disturbance of glycoprotein catabolism and leads to a clinical disease, AGU. The clinical features of AGU include slowly progressive psychomotor retardation starting at the age of 2.6 years and resulting in severe mental retardation before puberty. This psychomotor impairment is associated with the appearance of typical coarse facial features and degenerative changes in connective tissue (3). The disease was first described in two mentally retarded siblings in England (10). Subsequent patients have been found almost exclusively in Finland, where a total of 82 cases has been verified. Very recently, however, the first cases of AGU have been detected in the USA (9) and in Norway (12). The diagnosis of AGU has generally been based on the demonstration of increased urinary excretion of aspartylglycosylamine by chromatographic or electrophoretic methods (17). The same glycopeptide is the main storage material in brain and liver tissue, but small amounts of some higher glycoasparagines also accumulate (18)

The enzyme deficiency has been demonstrated in plasma and seminal fluid (21), as well as in liver, brain, and spleen tissue (19) of AGU patients. The enzyme defect is also expressed in cultured fibroblasts, which offers the possibility of prenatal diagnosis (2). Fibroblasts from parents of AGU patients have an intermediate activity of AADGase, which proves the autosomal recessive mode of inheritance of the disease and provides a basis for heterozygote detection (1)

In order to avoid the practical difficulties associated with cell culture techniques, we have assessed the suitability of plasma, leukocytes. and lymphocytes for the enzymatic diagnosis and carrier detection of $A G U$. Earlier data had already suggested that AADGase activity in the plasma of obligate heterozygotes was not different from control individuals (20).

\section{MATERIAL AND METHODS}

\section{PATIENTS}

The subjects studied consisted of 16 patients with clinically and biochemically verified AGU, 29 parents of patients (obligate heterozygotes), and 30 control individuals. At a later stage of the study, 31 healthy sibiings of $A G U$ patients and 11 offsprings of identified carriers whose spouses had normal AADGase values were investigated with the lymphocytes assay.

\section{PREPARATION OF SAMPLES}

Peripheral venous blood $(10 \mathrm{ml})$ was drawn into a heparinized syringe and used for the preparation of cell extracts. Leukocyterich plasma was separated from the erythrocytes by letting the syringe stand at room temperature for $60 \mathrm{~min}$. Leukocytes and plasma were then separated by centrifugation at $1,500 \mathrm{rpm}$ for 10 min. The celis were washed twice with phosphate-buffered saline before counting and sonication. Lymphocytes were separated from another $10-\mathrm{ml}$ blood sample by centrifugation using the one-step Ficoll-Isopaque method described by Böyum (5). The yield of lymphocytes from a 10-ml blood sample ranged from 12 to $83 \times$ $10^{6}$ cells. For elimination of possible erythrocyte contamination both lymphocytes and leukocytes were treated with $0.83 \%$ ammonium chloride for $15 \mathrm{~min}$ at $37^{\circ}$.

Cell extracts were prepared by sonication after adding Triton $\mathrm{X}-100$ to a final concentration of $0.1 \%$ to the cell suspension. The sonicates were used for enzyme assays and protein determination (13). For the plasma assays, aliquots of $200 \mu \mathrm{l}$ were used.

\section{ENZYME ASSAYS}

AADGase assay was originally described by Makino and coworkers (14), and a detailed account of our assay system has been reported (1). The synthetic substrate (2-acetamido- $N$ - (Laspart-4'-oyl)-2-deoxy- $\beta$-glucopyranosylamine) was kindly provided by Professor I. Yamashina (Kyoto University, Kyoto, Japan).

One unit of enzyme activity is defined as $1 \mathrm{nmol} N$-acetylglucosamine liberated $/ \mathrm{min} / \mathrm{g}$ sonicate protein: in plasma $1 U$ activity is expressed per m! plasma. $N$-Acetyl- $\beta$-glucosaminidase was assayed in all samples as a cell viability control using the commercially available $p$-nitrophenyl derivative as substrate (19). In most cases lymphocytes and leukocytes were separated and used for enzyme determinations immediately after the blood was drawn, otherwise the extracts were stored at $-70^{\circ}$ for $1-7$ days without loss of activity. In a few cases, the blood sample was kept overnight at room temperature. Storage of blood for periods longer than 24 hr was shown to decrease the enzyme activities.

\section{RESULTS}

\section{AADGase ACTIVITY IN LYMPHOCYTES}

All the AGU patients studied had unmeasurable or minimal AADGase activity in lymphocytes, with a mean of $3.9 \mathrm{U}$ (Fig. 1). This represents $3 \%$ of the mean activity in control samples. The highest activity of $16 \mathrm{U}$ was found in a 22 -year-old female patient. Unfortunately, the leukocytes and plasma of this case were not available for study.

The parents of AGU patients (obligate heterozygotes) showed AADGase activities ranging from 5 to $69 \mathrm{U}$, with a mean of 34.1 $\mathrm{U}$. An exceptionally low value of $5 \mathrm{U}$ was found in one mother. The blood in this case was stored overnight before lymphocyte separation which possibly accounts for the low enzyme activity.

AADGase activities in the lymphocytes of the control group ranged from 91 to $243 \mathrm{U}$, with a mean of $127.9 \mathrm{U}$, and were clearly separated from the values of the heterozygotes.

AADGase ACTIVITY IN LEUKOCYTES

All four AGU patients studied had unmeasurable AADGase activity in leukocytes. Obligate heterozygotes had enzyme levels closely similar to those in the lymphocytes from the same individuals, ranging from 1 to $65 \mathrm{U}$ with a mean of $38.8 \mathrm{U}$. However, the AADGase activity in the leukocytes of the control group displayed a much wider variation than that in the lymphocytes, ranging from 22 to $132 \mathrm{U}$ with a mean of $70.7 \mathrm{U}$. As depicted in Figure 1, there is considerable overlap between the leukocyte AADGase values of obligate heterozygotes and control individuals.

\section{AADGase ACTIVITY IN PLASMA}

AGU patients had undetectable or minimal activity of AADGase in their plasma samples also. The mean enzyme level of obligate heterozygotes was $72.2 \mathrm{U}$ and that of control indi- 


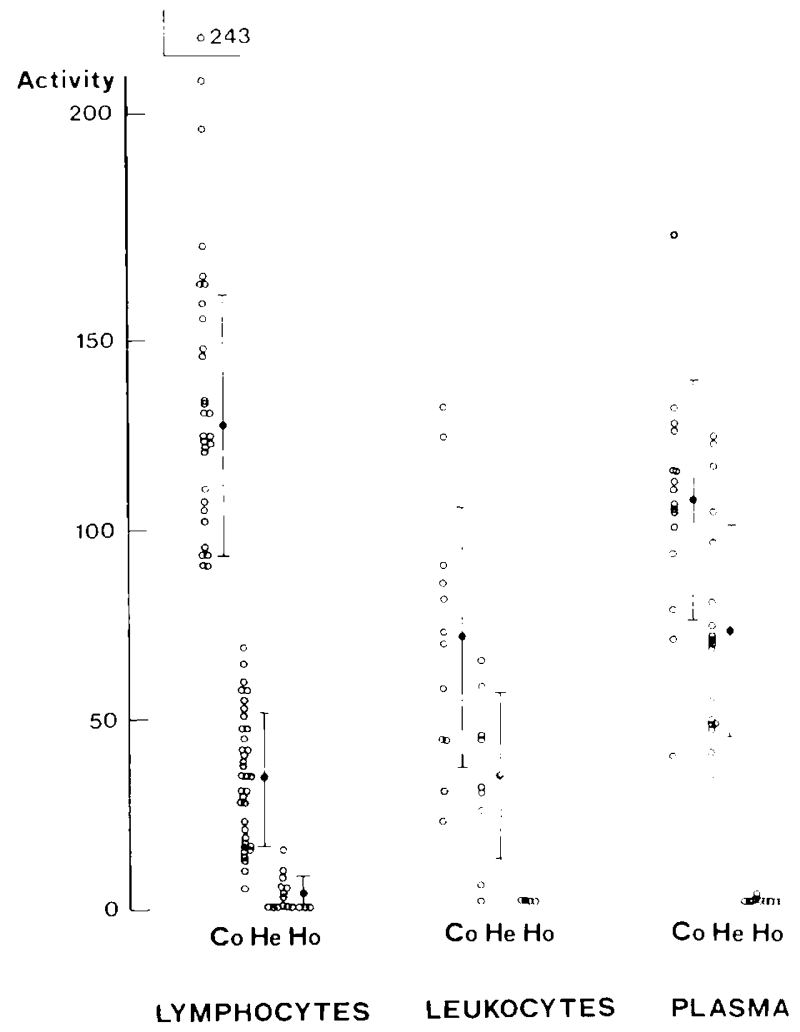

Fig. 1. Activity of 4-L-atspartylglycosylamine amido hydrolase in separaled lymphocyles, leukocytes, and plasma in three study groups. Co: control individuals; He: obligate heterozygotes (parents of pattients): $H O$ : homozygous aspartylglucosaminuria patients. Enzyme activity is expressed as nanomoles of $N$-acetylglucosamine liberated per min per g sonicate protein (or per $\mathrm{ml}$ plasma). Mean activity $\mathrm{SD}$ ) is given in separate bar.

viduals $107.2 \mathrm{U}$, but the overlap between the groups was extensive, as seen in Figure 1.

To conclude, the results indicate that homozygous deficiency of AADGase, i.e., aspartylglucosaminuria, can be reliably diagnosed using plasma, leukocytes, or separated lymphocytes. However. for carrier detection. only separated lymphocytes allow a satisfactory differentiation between heterozygotes and normal individuals.

\section{ACTIVITY OF N-ACETYI- $\beta$-CIILCOOSAMINIDASE}

$A$ several-fold increase in the activity of this enzyme was earlier found in liver and brain tissue of $A(i U$ patients (19). In the present study a slightly elevated level of $N$-acetyl- $\beta$-glucosaminidase was demonstrated in both leukocytes and lymphocytes, with a mean \pm SD of $18.9 \pm 5.3$ and $20.3 \pm 14.6 \mathrm{nmol} / \mathrm{min} / \mathrm{mg}$ protein. respectively. The corresponding values in the control group were $9.3 \pm 4.8$ and $12.3 \pm 5.5$, respectively. The activity of the enzyme in obligate heterozygotes was not different from the control group.

\section{AADGaSE IN LYMPHOCYTES OF REIATIVES OF AGU PATIENTS}

On the basis of the data presented above, AADGase assay using lymphocyte extracts was considered to fulfill the criteria of a reliable heterozygote test. The assessment of the genotype was based on the distribution of values in obligate heterozygotes: any individual with AADGase activity $3 \mathrm{SD}$ or more above the mean of obligate heterozygotes $(>87.2 \mathrm{U})$ was designated normal. The probability of a false negative carrier assessment with this criterion is $0.1 \%$ or less. Individuals with enzyme activity between 1.5 SD and $3 \mathrm{SD}$ above the mean of obligate heterozygotes (from 60.7 to $87.2 \mathrm{U}$ ) were called "inconclusive." In these cases the probability of a false negative carrier assessment is between $7.9 \%$ and $0.1 \%$ and restudy using a new lymphocyle sample or cultured skin fibroblasts is required. ADDGase activity less than 1.5 $\mathrm{SD}$ above the mean of obligate heterozygotes $(<60.7 \mathrm{U})$ was considered to indicate a carrier genotype. Using this value as the cutoff point, the risk of a normal individual being labeled a heterozygote was calculated to be $2.5 \%$ or less, based on the distribution of values in the control group. A similar carrier assessment system has been used by Kaback and coworkers in heterozygote screening projects for Tay-Sachs gene (1I).

A group of 31 siblings of verified AGU cases and II children of identified carriers whose spouses had normal AADGase activity were investigated using the lymphocyte enzyme assay. The observed number and frequency of heterozygotes was compared with those expected on the basis of Mendelian probabilities. The results are given in Table 1. The expected and observed frequencies of AGU carriers are closely similar, suggesting that the lymphocyte assay can be used reliably for carrier detection.

Two cases out of a total of 42 fell within the "inconclusive" range of AADGase activity. as shown in Figure 2. One daughter of an identified carrier had AADGase activity of $71 \mathrm{U}$ in the first assay, but in a later repeat study the activity was $123 \mathrm{U}$, indicating a normal AADGase genotype. The other "inconclusive" case was a female sibling of an $A G U$ patient having $A$ ADGase activity of $76 \mathrm{U}$. It has not yet been possible to perform a repeat test, but she is very likely a carrier because her daughter was shown to have lymphocyte AADGase activity of $40 \mathrm{U}$ and her husband, normal activity of $103 \mathrm{U}$

\section{DISCUSSION}

The demonstration of AADGase deficiency in plasma or in white cells has a number of practical implications. It offers an alternative method for the diagnosis of aspartylglucosaminuria. As mentioned earlier. this has so far been based on the demonstration of increased amounts of aspartylglucosylamine (AADG) in the urine. Screening tests for this purpose have been developed (8). Even though incrased AADG excretion has not been encountered under other conditions, demonstration of the enzyme defect is a more basic feature of the disease and thus preferable for diagnostic purposes. Furthermore, it is not known whether AADG excretion is elevated already during the "silent" period between birth and appearance of the lirst signs of the disease. The age of onset of clinical manifestations is known to be variable, ranging from some months to 6 years (3). Our results demonstrate that AGU patients have undetectable or minimal enzyme activity both in plasmat. buffy coat leukocytes, and separated lymphocytes. There was. however, some overlap between lymphocyte AADGase activity of $\mathrm{AGU}$ homozygotes and heterozygotes. It is therefore advisable to assay for AADGase both in plasma and in lymphocytes in the case of an asymptomatic newborn or infant suspected of being affected by $\mathrm{A}(\mathrm{iU}$

A practical and reliable carrier test of $A G U$ is needed, at least in Finland. where the disease is the most common known metabolic disorder leading to severe psychomotor retardation. The urinary excretion of AADG in obligate heterozygotes is not different from normal individuals (3) and thus the only possibility to show heterozygosity is the demonstration of intermediate levels of enzyme activity. The accuracy of our lymphocyte assay in AGU carrier identification appears to be adequate, as the observed frequency of carriers among the AGU relatives was in agreement with the theoretical expectations. This is the optimal method of evaluating a heterozygote detection method, as mentioned by Kaback and coworkers (11).

The incidence of $\mathrm{AGU}$ in Finland has been estimated roughly to be in the order of 1 in 26,000 (3), suggesting the overall carrier frequency of $A G U$ to be about 1 in 80 . We consider this too low to justify large scale screening programs for heterozygote detection, at least with the presently available methods. However, carrier detection among the relatives of known AGU patients is medically, economically, and psychologically advantageous, particu- 
Table 1. Carrier screening in close relatives of aspartylglucosaminuria $(A G U)$ patients by lymphocyte test

\begin{tabular}{|c|c|c|c|c|c|c|}
\hline $\begin{array}{l}\text { Relationship } \\
\text { to patient }\end{array}$ & $\begin{array}{c}\text { Frequency } \\
\text { expected }\end{array}$ & No. tested & Carriers & Inconclusive & Noncarriers & $\begin{array}{c}\text { Frequency } \\
\text { observed }\end{array}$ \\
\hline Parent & 1.0 & 29 & 29 & & & 1.0 \\
\hline Sibling & 0.67 & 31 & 22 & $1^{1}$ & 8 & 0.71 \\
\hline Offspring of sibling ${ }^{2}$ & 0.5 & 11 & 5 & $1^{3}$ & 5 & 0.45 \\
\hline Husband/wife of sibling & Unknown & 9 & & & 9 & 0 \\
\hline
\end{tabular}

' 4-L-Aspartylglucosamine amido hydrolase (AADGase) $76 \mathrm{U}$; repeat test not performed; probable carrier (see text).

${ }^{2}$ One parent (sibling of AGU patient) is identified carrier, the other parent has normal AADGase activity.

${ }^{3}$ AADGase $71 \mathrm{U}$; repeat test $123 \mathrm{U}$; noncarrier

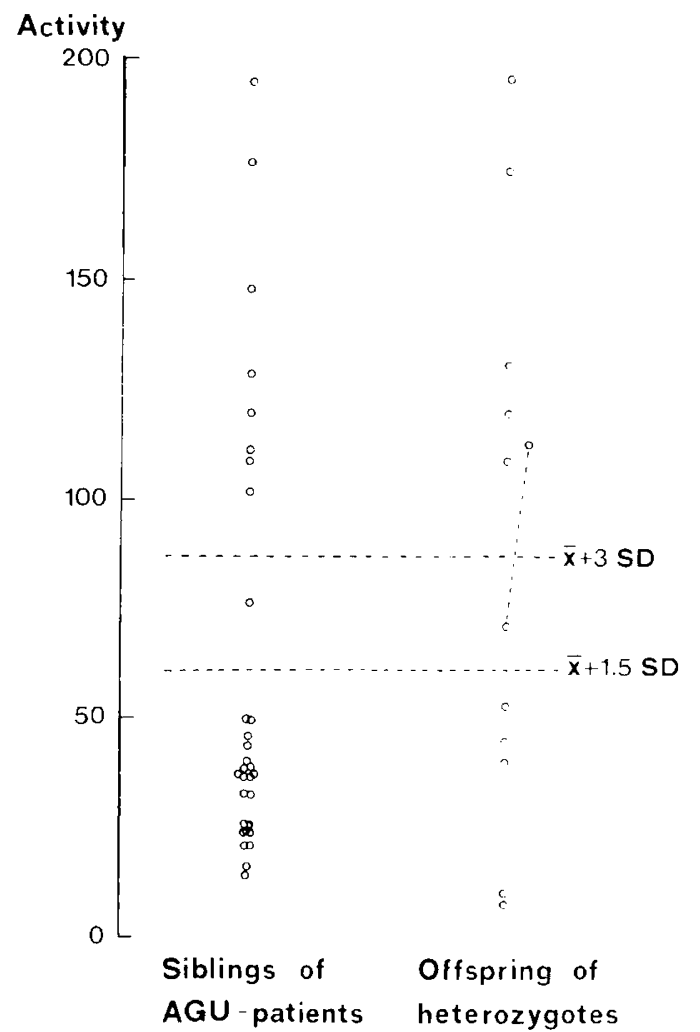

Fig. 2. Activity of 4-L-aspartylglycosylamine amido hydrolase in lymphocytes of close relatives of aspartylglucosaminuria patients. Values above the upper dotted line showing the mean activity $+3 \mathrm{SD}$ of obligatc heterozygotes indicate normal genotype, values below mean heterozygote activity +1.5 SD indicate carrier genotype. Enzyme activities falling between the two lines comprise the "inconclusive" cases (see text)

larly since prenatal diagnosis and the possibility of preventive abortion can be offered to carrier-carrier matings.

The use of separated lymphocytes for heterozygote detection has previously been reported only in Gaucher's disease (4). Distinction of heterozygotes from normal individuals by $\beta$-glucosidase activity was clearly better with Ficoll-separated lymphocytes than with mixed leukocytes or granulocytes. Even with lymphocytes there was some overlap between the enzyme activities in the two groups.

In a majority of inherited enzyme defects, particularly those of lysosomal hydrolases, heterozygous levels of the enzyme activity are demonstrable in an easier fashion using either serum (plasma) as in Tay-Sachs' disease and Krabbe's disease or buffy coat leukocytes as in metachromatic leukodystrophy, Fabry's disease, Niemann-Pick's disease, Wolman's disease, and in some other genetic enzyme defects (see Reference 6).

In acid phosphatase deficiency, separated lymphocytes (glass bead column separation) could not be reliably used to distinguish heterozygotes from normal individuals, but after $56 \mathrm{hr}$ of culture with phytohemagglutinin stimulation a distinct differentiation was possible (16). Also in glycogenosis type II unstimulated lymphocytes were not suitable for the demonstration of the heterozygous level of $\alpha$-glucosidase activity, but in phytohemagglutininstimulated lymphocytes the heterozygotes could be distinguished (7).

The lymphocytes constitute a more homogeneous cell population than leukocytes, which probably accounts for the better distinction of AADGase activity in heterozygotes and normal individuals. It is possible that enzyme assays in separated lymphocytes could offer possibilities for heterozygote detection in some other lysosomal storage diseases in which serum or leukocytes are not suitable for that purpose. For instance, in mannosidosis, heterozygote and normal levels of $\alpha$-mannosidase activity in serum and leukocytes had considerable overlap, and distinction of heterozygotes and normal individuals could be achieved only by calculating ratios between $\alpha$-mannosidase and other lysosomal enzymes (15).

\section{SUMMARY}

Assay of activity of 4-L-aspartylglycosylamine amido hydrolase in peripheral blood lymphocytes was found to be reliable for heterozygote detection of aspartylglucosaminuria. Enzyme levels in buffy coat leukocytes, on the other hand, could not distinguish heterozygotes from normal individuals. AGU patients had minimal or nondetectable activity of AADGase in lymphocytes, leukocytes, and plasma. A group of siblings of AGU patients and of children of identified carriers were investigated with the lymphocyte assay for AADGase. The observed number of heterozygotes was in good agreement with expectations based on Mendelian probabilities. AADGase assay in separated lymphocytes offers possibilities for heterozygote screening among selected high gene frequency populations.

\section{REFERENCES AND NOTES}

1. Aula, P., Autio, S., Raivio, K., and Näntö, V.: Detection of heterozygotes for aspartylglucosaminuria ( $\mathrm{A} \mathrm{GU})$ in cultured fibroblasts. Humangenetik, 25: 307 (1974).

2. Aula, P., Näntö, V.. Laipio, M.-L., and Autio, S.: Aspartylglucosaminuria: Deficiency of aspartylglucosaminidase in cultured fibroblasts of patients and their heterozygous parents. Clin. Genet., 4: 297 (1973).

3. Autio, S.: Aspartylglucosaminuria: Analysis of thirty-four patients. J. Ment Defic. Res. Monogr. Ser., 1: 1 (1972).

4. Beutler, E. and Kuhl, W.: The diagnosis of the adult type of Gaucher's disease and its carrier state by demonstration of deficiency of $\beta$-glucosidase activity in peripheral blood leukocytes. J. Lab. Clin. Med., 76: 747 (1970).

5. Böyum, A.: Separation of leukocytes from blood and bone marrow. Scand. J. Clin. Lab. Invest., 21(suppl 97): 1 (1968)

6. Hers, H. G., and Van Hoof, F. (Eds.): Lysosomes and Storage Diseases (Academic Press, New York, 1973).

7. Hirschhorn, K., Nadler, H. L., Waithe, W. I., Brown, B., and Hirschhorn, R. Pompe's disease: Detection of heterozygotes by lymphocyte stimulation. Science, 166: 1632 (1969).

8. Humbel, R., and Marchal, C.: Screening test for aspartylglucosaminuria. J. Pediat., 84: 456 (1974).

9. Isenberg, J. N., and Sharp, H. L.: Aspartylglucosaminuria: Psychomotor retardation masquerading as a mucopolysaccharidosis. J. Pediat., 86: 713 (1975). 
10. Jenner, F. A., and Pollitt, R. J.: Large quantities of 2-acetamido-1-(beta-L-aspartamido)-1,2-dideoxyglucose in the urine of mentally retarded siblings. Biochem. J., 103: $48(1967)$

11. Kaback, M. M., Zeiger, R. S., Reynolds, L. W., and Sonneborn, M.: Approaches to the control and prevention of Tay-Sachs disease. In: A. G. Steinberg and A G. Bearn: Progress in Medical Genetics, Vol. X, p. 103 (Grune and Stratton, New York, 1974).

12. Lie, S.: Personal communication, 1975

13. Lowry, A., Rosebrough, N. J., Farr, A. L., and Randall, R. J.: Protein measurement with Folin phenol reagent. J. Biol. Chem., 190: 265 (1951).

14. Makino, M.. Kojima, T., and Yamashina, I.: Enzymatic cleavage of glycopeptides. Biochem. Biophys. Res. Commun., 24: 961 (1966)

15. Masson, P., Lundblad, A., and Autio, S.: Mannosidosis: Detection of the disease and of heterozygotes using serum and leukocytes. Biochem. Biophys. Res. Commun., 56: 296 (1974)

16. Nadler, H. L.: Acid phosphatase deficiency. In: H. G. Hers and F. Van Hoof: Lysosomes and Storage Diseases (Academic Press, New York, 1973).

17. Palo, J., and Mattson, K.: Chromatographic isolation of 2-acetamido-1-(beta ${ }^{2}-\mathrm{L}$ aspartamido)-1,2-dideoxyglucose from urine. J. Chromatogr., 50: 534 (1970).
18. Palo, J., Pollitt, R. J., Pretty, K. M., and Savolainen, H.: Glycoasparagine metabolites in patients with aspartylglucosaminuria: Comparison between English and Finnish patients with special reference to storage materials. Clin. Chim. Acta, 47: 69 (1975)

19. Palo, J., Riekkinen, P.. Arstila. A. U., Autio, S., and Kivimäki, T.: Aspartylglucosaminuria. II. Biochemical studies on brain, liver, kidney and spleen. Acta Neuropathol (Berlin), 20:217 (1972).

20. Pollitt, R. J., and Jenner, F. A.: Enzymatic cleavage of 2-acetamido-1-(beta ${ }^{1}$ L-aspartamido)-1,2-dideoxy-beta-D-glucose by human plasma and seminal fluid: Failure to detect the heterozygous state for aspartylglucosaminuria. Clin Chim. Acta, 25: 413 (1969).

21. Pollitt, R. J., Jenner, F. A., and Merskey, H.: Aspartylglucosaminuria: An inborn error of metabolism associated with mental defect. Lancet, ii: 253 (1968).

22. This study was supported by grants from Sigrid Jusélius Foundation and the National Research Council for Medical Sciences, Finland.

23. Requests for reprints should be addressed to: P. Aula, M.D., Children`s Hospital, 00290 Helsinki 29 (Finland).

24. Accepted for publication January 14, 1976
$\beta$-Galactosidase heterozygote Hurler syndrome
$\alpha$-L-iduronidase leukocytes

\title{
Hurler Syndrome: $\alpha$-L-Iduronidase Activity in Leukocytes as a Method for Heterozygote Detection
}

\author{
REBECCA S. WAPPNER ${ }^{129}$ AND IRA K. BRANDT
}

Departments of Pediatrics and Medical Genetics, Indiana University School of Medicine, Indianapolis, Indiana, USA

\section{Extract}

$\alpha$-L-Iduronidase activity and $\beta$-galactosidase activity were determined in mixed leukocyte preparations in $\mathbf{1 0}$ families in which the Hurler syndrome had occurred. Affected patients, heterozygotes, and normal subjects were clearly distinguished by $\alpha$-L-iduronidase activity alone. Patients had 0-3\%, obligate heterozygotes 19-60\%, and normal subjects $83-121 \%$ of the mean normal activity. There was no overlap between heterozygotes and normal subjects. Although the mean $\alpha$-L-iduronidase to $\beta$-galactosidase ratio was significantly lowered in heterozygotes when compared with that of normal subjects, appreciable overlap was noted between the two groups.

\section{Speculation}

Carriers and affected individuals for Hurler syndrome can be reliably detected using mixed leukocyte preparations for the determination of $\alpha$-L-iduronidase activity. As technology improves enzyme assays will become reliable enough for determination of heterozygotes for an increasing number of disorders, thus enabling more thorough and accurate genetic counseling.

The Hurler and Scheie syndromes (mucopolysaccharidosis IH and IS, respectively) are autosomal-recessive disorders characterized by deficient activity of the lysosomal enzyme (ec. 3.2.1.76) $\alpha$-L-iduronidase $(2,9,14,16)$. This enzymatic defect results in generalized lysosomal accumulation and excessive urinary excretion of partially degraded mucopolysaccharides containing iduronic acid residues: heparan sulfate and dermatan sulfate $(6,8)$.

Using phenyl- $\alpha$-L-iduronide as a substrate, $\alpha$-L-iduronidase activity has been demonstrated to be reduced in leukocytes, serum, and cultured skin fibroblasts from obligate heterozygotes for the Hurler and Scheie syndromes (9, 14). Hall and Neufeld (9) demonstrated that the $\alpha$-L-iduronidase activity of Hurler heterozygous cultured skin fibroblasts varied from 20 to $95 \%$ of normal, with a mean value of $46 \%$. This range overlapped that of material obtained from normal control subjects. Liem and Hooghwinkel (14) demonstrated $\alpha$-L-iduronidase activity of 30 and $53 \%$ of normal control subjects in mixed leukocyte preparations from two Hurler obligate heterozygotes. Singh et al. (17) have reported $\alpha$-L-iduronidase activity in serum of one Hurler obligate heterozygote and one Scheie obligate heterozygote of 12 and $19 \%$ of normal, respectively.

Although it is known that other lysosomal enzymes differ in specific activity among different leukocyte cell types $(3,12)$ and that factors resulting in a change from the normal differential may affect the reliability of carrier detection when mixed leukocyte preparations are used, no data have been published concerning the relative distribution of $\alpha$-L-iduronidase among various leukocyte cell types.

We report a modified assay for $\alpha$-L-iduronidase activity which employs mixed leukocyte preparations. The assay was used for controlled studies of families in which the Hurler syndrome has occurred and appears to be sufficiently accurate and precise to enable the detection of heterozygosity with greater than $95 \%$ confidence. 